\title{
Psychiatric Comorbidity in Transformed Migraine: Presentation, Treatment, Impact and Outcome
}

\author{
Muhammad A. Abbas M.D \\ Thomas Jefferson University \\ Haseeba Ismaiel, M.D \\ Thomas Jefferson University \\ William B. Young M.D. \\ Thomas Jefferson University \\ Mary Hopkins \\ Thomas Jefferson University \\ Stephen D. Silberstein, M.D \\ Thomas Jefferson University \\ Follow this and additional works at: https://jdc.jefferson.edu/jeffjpsychiatry \\ Part of the Psychiatry Commons \\ Let us know how access to this document benefits you
}

\section{Recommended Citation}

Abbas M.D, Muhammad A.; Ismaiel, M.D, Haseeba; Young M.D., William B.; Hopkins, Mary; and Silberstein, M.D, Stephen D. (2010) "Psychiatric Comorbidity in Transformed Migraine: Presentation, Treatment, Impact and Outcome," Jefferson Journal of Psychiatry. Vol. 23 : Iss. 1 , Article 3.

DOI: https://doi.org/10.29046/JJP.023.1.003

Available at: https://jdc.jefferson.edu/jeffjpsychiatry/vol23/iss1/3

This Article is brought to you for free and open access by the Jefferson Digital Commons. The Jefferson Digital Commons is a service of Thomas Jefferson University's Center for Teaching and Learning (CTL). The Commons is a showcase for Jefferson books and journals, peer-reviewed scholarly publications, unique historical collections from the University archives, and teaching tools. The Jefferson Digital Commons allows researchers and interested readers anywhere in the world to learn about and keep up to date with Jefferson scholarship. This article has been accepted for inclusion in Jefferson Journal of Psychiatry by an authorized administrator of the Jefferson Digital Commons. For more information, please contact: JeffersonDigitalCommons@jefferson.edu. 


\title{
PSYCHIATRIC COMORBIDITY IN TRANSFORMED MIGRAINE:
}

PRESENTATION, TREATMENT, IMPACT AND OUTCOME

\author{
Muhammad A. Abbas M.D., Haseeba Ismaiel, M.D. William B. Young M.D., Mary \\ Hopkins, Stephen D. Silberstein, M.D. \\ Jefferson Headache Center, Thomas Jefferson University.
}

\section{INTRODUCTION}

Transformed migraine is one of the subtypes of chronic daily headache $(\mathrm{CDH})$, and is similar to chronic migraine, described in the new International Headache Society (IHS) classification

2004. ${ }^{1}$ The term CDH refers to the Headache disorders experienced 15 or more days a month and includes headaches associated with medication overuse. ${ }^{2,3} \mathrm{CDH}$ can be divided into primary and secondary varieties. Primary $\mathrm{CDH}$ is not related to a structural or systemic illness. It includes diseases such as Transformed migraine (TM). Chronic tension-type headache (CTTH), new daily persistent headache (NDPH), and hemicrania continua (HC). Secondary CDH has an identifiable underlying cause, including post-traumatic headache, cervical spine disorders, vascular disorders, nonvascular intracranial disorders and headaches associated with temporomandibular joint disorders, sinus infections, chronic meningitis, low and high intracranial pressure. In this 
study we have adopted the 1996 definition of TM proposed by Silberstein and Lipton in preference to the new discredited 2004 IHS criteria for chronic migraine.

The association between migraine and psychiatric disorders has long been established.

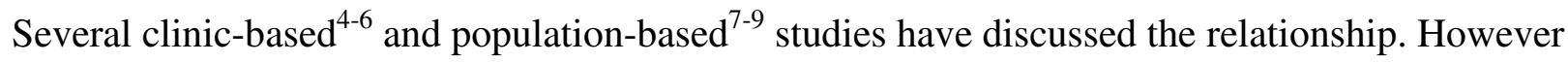
psychiatric comorbidity in transformed migraine has seldom been discussed, and the effect on overall outcome has not been examined . Population based studies have shown that $4 \%$ to $5 \%$ of the general population has primary $\mathrm{CDH} .{ }^{10}$ Transformed migraine is the major cause of $\mathrm{CDH}$ and is associated with poor quality of life and greater medical and social expenses compared to episodic migraine. ${ }^{11,12} \mathrm{CDH}$ is most commonly transformed Migraine and is accompanied by high anxiety levels in most patients and with hysterical traits in some. These patients frequently have a coexisting depressive disorder. ${ }^{12}$ The purpose of this study is to characterize psychiatric disorders accompanying TM in a tertiary headache center and to examine their impact on outcome.

\section{Patients and Methods}

One hundred and thirty nine consecutive patients of Transformed Migraine (Defined by Silberstein Lipton criteria) attending a quaternary headache center were offered entry into the study. Their headache history was taken by a neurologist. Each patient had a diagnostic semi 
structured psychiatric interview by a psychiatrist or psychologist, a Beck Depression Inventory (BDI), Migraine Disability Assessment Score (MIDAS), and a SF-36.

At 3, 6, and 12 months, headache frequency, intensity scores, BDI, MIDAS, and SF-36 scores were measured. MIDAS and SF-36 have been validated in previous headache studies and are sensitive to clinical change. ${ }^{13,14}$ The BDI is a standardized test and also validated to diagnose the presence of depression.

The headache severity index was calculated by multiplying number of days with baseline headache by the baseline intensity and adding the number of days with a headache exacerbation multiplied by the exacerbation intensity and divided by 30 days. The data was then analyzed using SAS and regression analysis.

\section{RESULTS}

Overall 82 subjects consented to the study. 69 were women (84\%) and 13 were men (16\%). With a mean age of $39.7 \pm 13.2$ years. The mean age of onset of episodic migraine was $18.6 \pm 11.5$ years and mean duration of daily headache was $7.0 \pm 8.0$ years. Aura was present in 23 patients (28\%) (16 visual, 1 sensory, and 6 mixed). 86.6\%(71 Pts) of the study population over used acute treatment, with a mean duration of overuse of $4.3 \pm 5.4$ years. The mean initial headache frequency was $23.2 \pm 6.1$ days. At twelve months, the mean headache frequency decreased to 
13.4 \pm 11.1 days. The mean initial baseline headache intensity was $5.7 \pm 2.0$ out of 10 , at twelve months, the mean baseline headache intensity decreased to 5.1 \pm 1.9 . The baseline mean exacerbation headache frequency and intensity was $6.2 \pm 5.9$ and $7.8 \pm 3.4$, respectively. At twelve months the mean exacerbation headache frequency and intensity decreased to $4.0 \pm 4.2$ and $7.6 \pm 1.8$ respectively. The headache severity index was $6.5 \pm 1.5$ at headache onset and $4.5 \pm 2.5$ at 12 months ( $\mathrm{p}<0.0001$ for difference, Dunnett's method for multiple comparisons.

We classified the 82 patients enrolled in the study into three categories of response to treatment, high, intermediate and low. High response was defined as a decrease in headache severity of 4.73 or greater. Intermediate response, based on severity change between 0.83 and 4.73 and low response, based on severity changes less then 0.83 on the 11 point VAS scale. Based on this response criteria 29 subjects had a high response, 36 an intermediate response and 17 a low response (Figure 1). Age can not predict outcome as patients with young age showed both type of response, high as well as low and patients with middle age group had intermediate response (Figure 2).

The highest change in headache severity index occurs with patients who had worst headache score at baseline, showed by Kruskal-Wallis test for non-parametric analysis. (Figure 3). The Beck Depression Inventory (BDI) scores varied widely with an initial range of 0-44, and it decreased gradually between six months but slightly increased at 12 months but all were still less than at baseline. (Figure 4). Patients with low BDI score at baseline had a good outcome (Figure 
5). SF-36 results showed a varied response among its various sub-categories and was not a good predictor of outcome but was a good measurement of outcome.( Figure 6 ). The MIDAS scores were predominantly in Grade IV with $78 \%$ (n=58) scoring greater than 21 at the initial evaluation. A number of subjects improved to a Grade I-III at 3 and 6 months (Figures 7).

Most patients had psychiatric comorbidity, seventy-two patients (88\%) had at least one Axis I diagnosis. The most common diagnostic groups were Adjustment Disorder ( $\mathrm{n}=35)$, Depression $(\mathrm{n}=22)$, and Generalized Anxiety Disorder GAD $(\mathrm{n}=14)$ (Figure 8). In utilizing 3 categories of high/intermediate/low response, patients with Adjustment disorder showed low response in 55\% of cases as compared to $38 \%$ in each of high and lintermediate response categories. $17 \%$ of Depressed patients showed high response, 33\% intermediate and $18 \%$ low response. $11 \%$ of GAD patients showed high response, $18 \%$ intermediate and $12 \%$ low response, as compared to patients with no Axis 1 psychiatric disorder 22\% showed high response, $8 \%$ intermediate and 6\% low response.

\section{DISCUSSION}

On Transformed Migraine patients had severe disability which profoundly affected their function and quality of life. Patients improved with treatment but still had significant pain, disability, and poor quality of life. 
For chronic migraine (CM) the requirement that the daily headache must meet the criteria for migraine without aura each day remains a concern with the first revision of the new proposed IHS criteria, which captures only a small number of patients with TM, as even episodic migraine does not always meet IHS migraine criteria throughout the attack. ${ }^{1}$ For that reason we adopted Silberstein and Lipton revised Criteria for transformed migraine, stating that patients should have daily or almost daily ( $\geq 15 \mathrm{~d} / \mathrm{mon})$ head pain for $\geq 1$ month with average headache duration $\geq 4$ $\mathrm{h}$ /day with at least one of the following 1) history of episodic migraine meeting an IHS criteria 1.1 to 1.6 .2 ) history of increasing Headache frequency with decreasing severity of migrainous features or headache at one time meets IHS criteria for migraine but it doesn't meet criteria for new daily persistent headache or hemicrania continua and is not attributed to another disorder. Our study is consistent with other studies showing high prevalence of psychiatric comorbidity in Transformed Migraine. ${ }^{15}$ Regardless of psychiatric comorbidity our patients severity and intensity of headache decreased by time as is indicated by Figure 3. Treatment outcome cannot be predicted based upon initial severity, depression, disability, or quality of life.

We found no difference between drug-overusers and non overusers in outcome. ${ }^{16}$ As most of our patients were drug overusers and the mean duration of their analgesic overuse was several years. Their final assessment scores varies widely and many of them improved regardless of their acute drug use. 
Overall disability, physical health and social functioning are more impaired in TM than in many other chronic illness. ${ }^{17,18}$ Our study showed some improvement in disability scores and total headache days which decreased from an average of 23.2 to 13.4 headache days per month. Patients still had $1 / 3$ of the month with pain along with substantial social mal-functioning and physical ill health after 12months follow up. Previous studies using the SF-36 in headache patients, showed that patients with TM had the worst pain profile. SF-36 scale scores were most severely reduced in patients with TM, followed by CTTH and episodic migraine. ${ }^{19}$ Effective management of episodic migraine might prevent its progression to the more disabling $\mathrm{TM}^{20}$

Overall $86.6 \%$ of our TM patients had a coexisting psychiatric disorder this is similar to the $90 \%$ that Verri et al found. ${ }^{21}$ Most common were adjustment disorders, Depression and generalized anxiety disorders (Fig 8)

Overall outcome could not be predicted on initial severity and coexisting illnesses, but comorbid psychiatric diseases have important treatment implications. TM requires a combination of both pharmacological and behavioral treatment. ${ }^{22}$ Psychiatric comorbidity demands that a comprehensive treatment approach is needed.

Depression can be a consequence of living with chronic, disabling headaches and may respond as headaches improve. However preexisting headache or anxiety may precipitate or exacerbate headache episodes in patients who are headache-prone. Headaches or affective distress may not improve until the comorbid psychopathology improves. ${ }^{23}$ Our study supports the view that 
combined psychologic and pharmacologic treatment need to be considered. ${ }^{24,25}$ Relaxation or biofeedback training and short-term cognitive-behavioral therapy are particularly useful.

Cognitive-behavioral headache treatment may include focused attention on the specific psychological problems that precipitate or exacerbate headache episodes or interfere with the treatment compliance. The role of antidepressants in chronic headache with comorbid psychiatric illness, is supported by several studies. ${ }^{26} \mathrm{We}$ frequently use antidepressants combined with psychotherapies, such as stress management, behavior-relaxation therapy, biofeedback may be affective adjuvant treatment of transformed migraine. 
Fig 1: Based on response criteria describes in methods, 29 subjects showed high response, 36

intermediate response and 17 low response

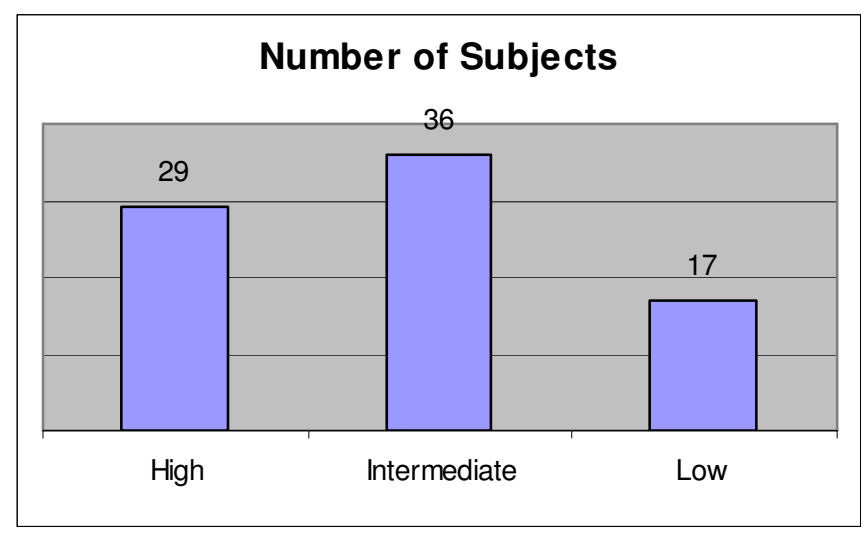


FIGURE 2: Age can not predict outcome as patients with young age showed both type of response high as well as low and patients with middle age group had an intermediate response

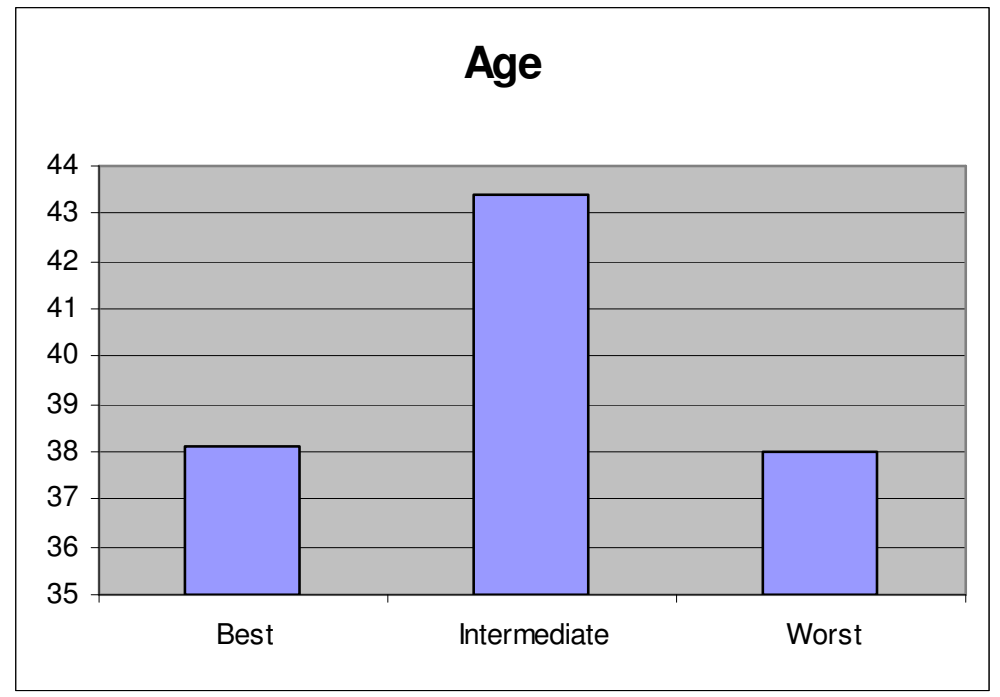


FIGURE 3: The Kruskal-Wallis test for non-parametric analysis of this data demonstrated the highest change in headache severity index occurs with patients who had worst headache score at baseline

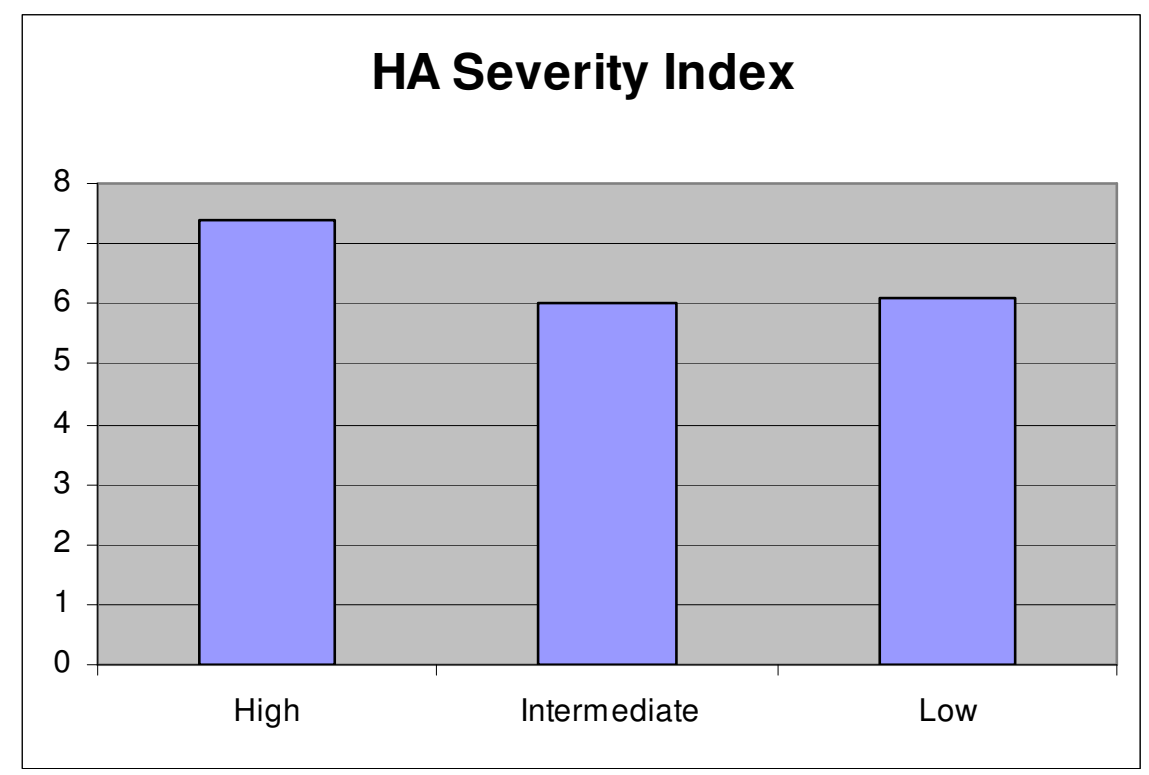


FIGURE 4: The Beck Depression Inventory (BDI) scores varied widely with an initial range of $0-44$, and it decreased gradually till six months then slightly increased at 12 months but all patients were still less than baseline.

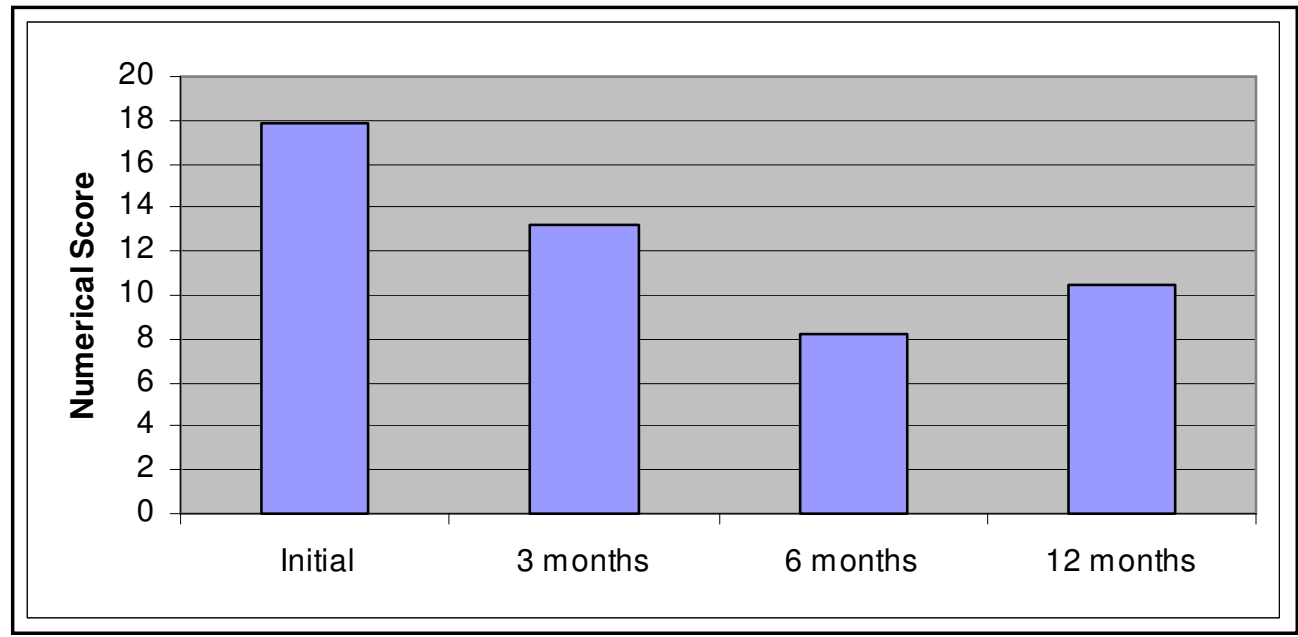


FIGURE 5: Patients with low BDI score at baseline showed good response at outcome

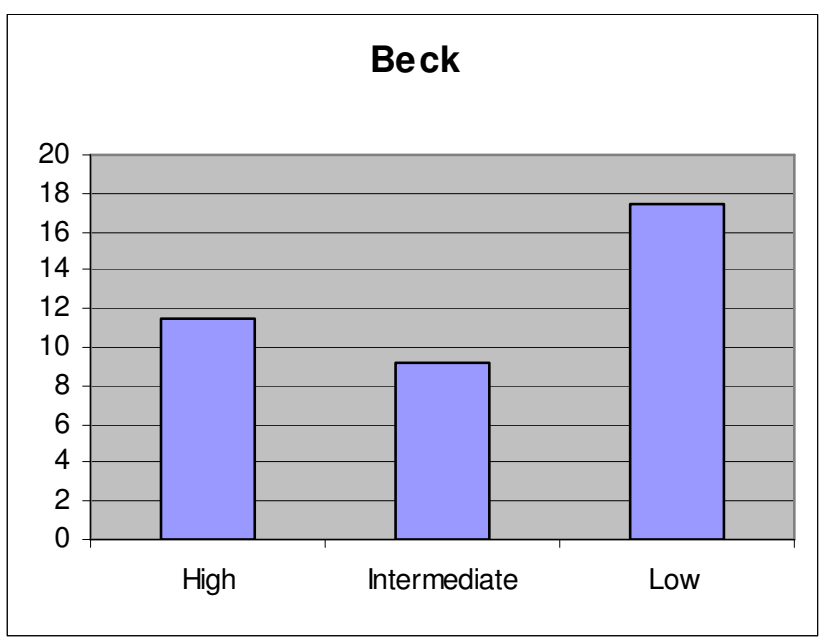


FIGURE 6: SF-36 Results, SF-36 results showed a varied response among its various sub-

categories and was not a good predictor of outcome, but a good measurement of outcome.

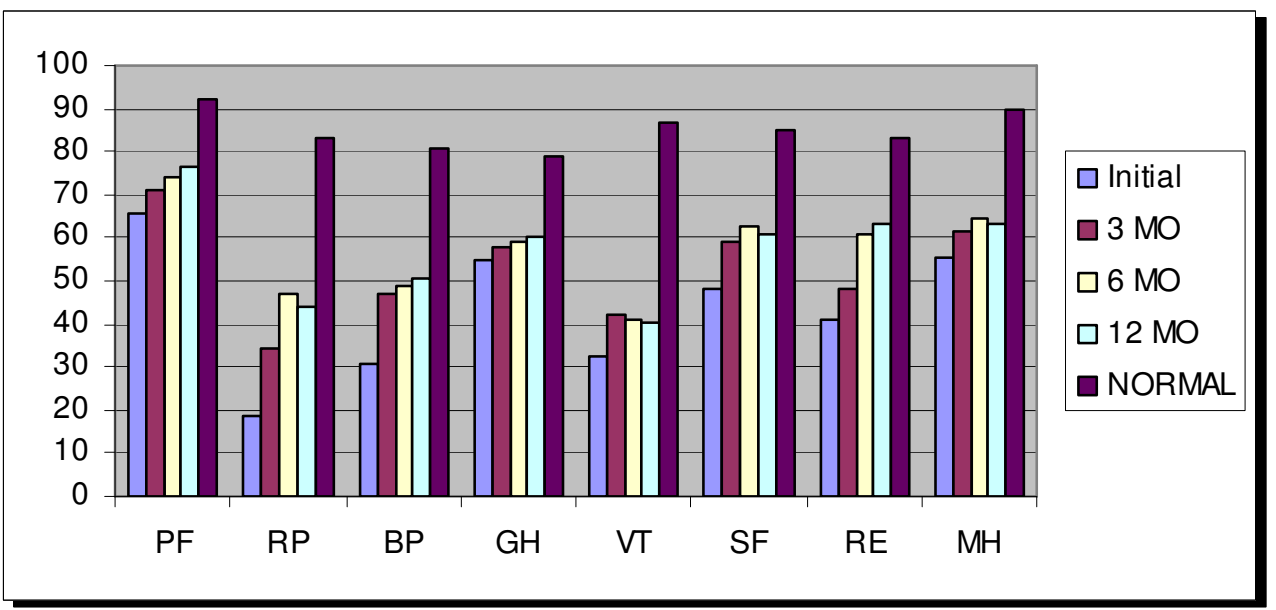


FIGURE 7: The MIDAS scores were predominantly in Grade IV with 78\% ( $\mathrm{n}=58)$ scoring greater than 21 at the initial evaluation. The trend showed that a number of subjects improved to a Grade I-III at 3 and 6 months

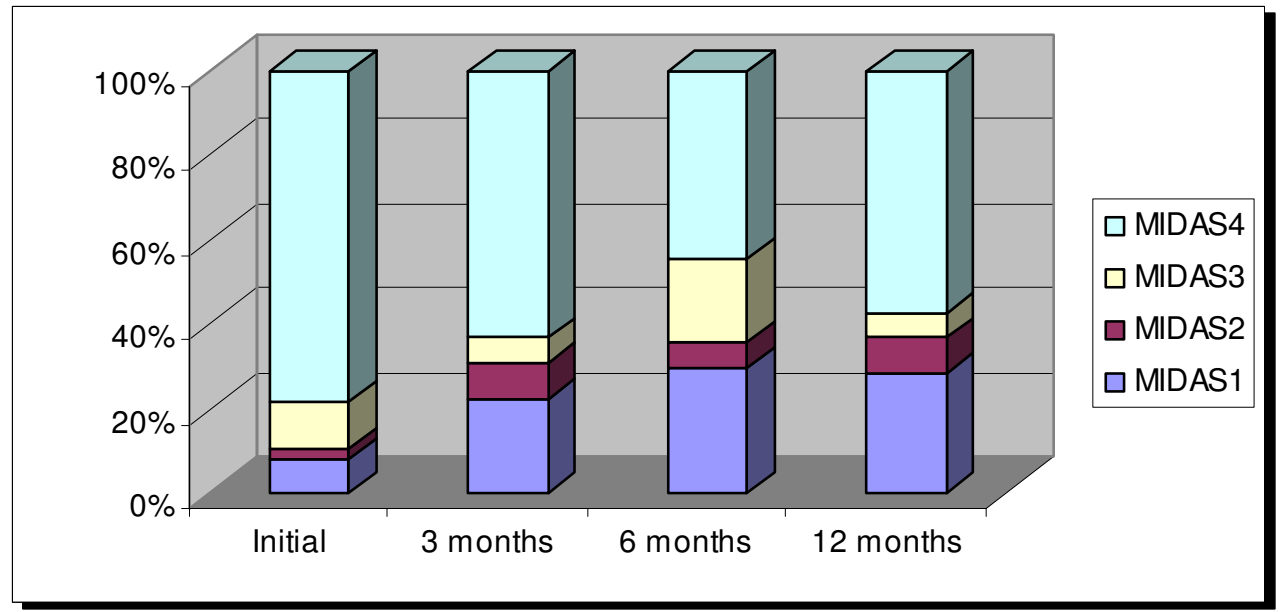


FIGURE 8: seventy-two patients (88\%) had at least one Axis I diagnosis. The most common diagnostic groups were Adjustment Disorder ( $\mathrm{n}=35$ ), Depression $(\mathrm{n}=22)$, and Generalized Anxiety Disorder GAD ( $\mathrm{n}=14)$

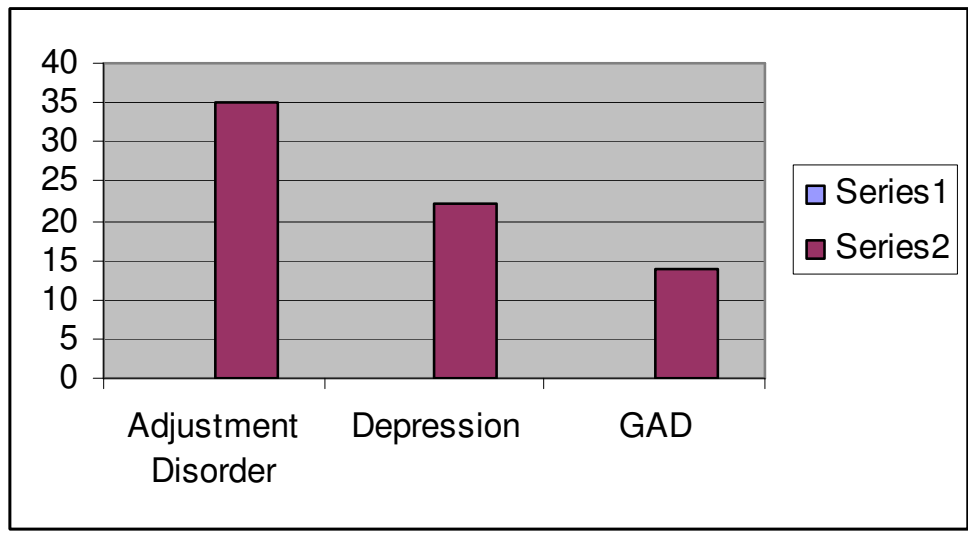

\section{Psychiatric comorbidity}

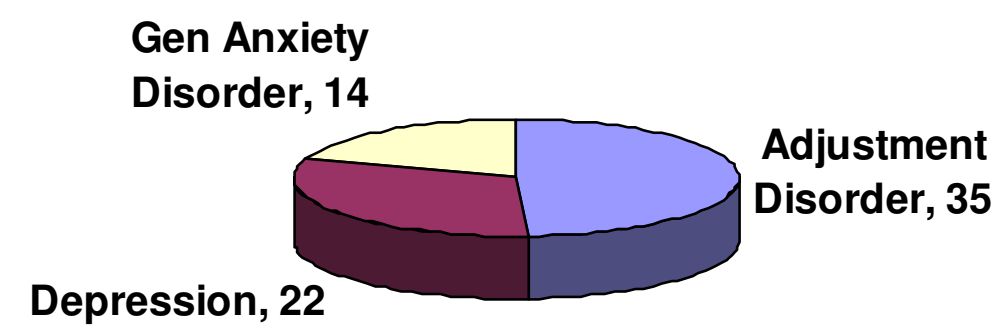




\section{REFERENCES}

\section{Reference List}

1. Headache Classification Committee. The International Classification of Headache Disorders, 2nd Edition. Cephalalgia 2004; 24(Suppl 1):1-160.

2. Silberstein SD, Lipton RB, Sliwinski M. Classification of daily and near-daily headaches: field trial of revised IHS criteria. Neurology 1996; 47:871-875.

3. Silberstein SD, Lipton RB, Solomon S, Mathew NT. Classification of daily and near daily headaches: proposed revisions to the IHS classification. Headache 1994; 34:1-7.

4. Marazziti D, Toni C, Pedri S, Bonuccelli U, Pavese N, Nuti A et al. Headache, panic disorder and depression: comorbidity or a spectrum? Neuropsychobiology 1995; 31(3):125129.

5. Mitsikostas DD, Thomas AM. Comorbidity of headache and depressive disorders. Cephalalgia 1999; 19:211-217.

6. Juang KD, Wang SJ, Fuh JL, Lu SR, Su TP. Comorbidity of depressive and anxiety disorders in chronic daily headache and its subtypes. Headache 2000; 40(10):818-823.

7. Merikangas KR, Merikangas JR, Angst J. Headache syndromes and psychiatric disorders: associations and familial transmission. J Psychiatric Res 1993; 27:197-210.

8. Lipton RB, Hamelsky S, Kolodner KB, Steiner TJ, Stewart WF. Migraine, quality of life, and depression: a population-based case-control study. Neurology 2000; 55(5):629-635.

9. Devlen J. Anxiety and depression in migraine. J R Soc Med 1994; 87(6):338-341.

10. Mathew NT, Stubits E, Nigam MR. Transformation of episodic migraine into daily headache: analysis of factors. Headache 1982; 22:66-68.

11. Kono S, Mayer JS, Margi??? CM. Transformed migraine is a cause of chronic daily headache. Headache 1999; 39(2):95. (Abstract)

12. Mongini F, Defilippi N, Negro C. Chronic daily headache. A clinical and psychologic profile before and after treatment. Headache 1997; 37:83-87.

13. Guitera V, Munoz P, Castillo J, Pascual J. Quality of life in chronic daily headache: a study in a general population. Neurology 2002; 58(7):1062-1065. 
14. D'Amico D, Usai S, Grazzi L, Rigamonti A, Solari A, Leone M et al. Quality of life and disability in primary chronic daily headaches. Neurol Sci 2003; 24 Suppl 2:S97-100.

15. Magnusson T. Extracervical symptoms after whiplash trauma. Cephalalgia 1994; 14(3):223-227.

16. Monzon MJ, Lainez MJ. Quality of life in migraine and chronic daily headache patients. Cephalalgia 1998; 18(9):638-643.

17. Solomon GD. Evolution of the measurement of quality of life in migraine. Neurology 1997; 48(Suppl 1):2-5.

18. Pini LA, Cicero AF, Sandrini M. Long-term follow-up of patients treated for chronic headache with analgesic overuse. Cephalalgia 2001; 21(9):878-883.

19. Wang SJ, Fuh JL, Lu SR, Juang KD. Quality of life differs among headache diagnoses: analysis of SF-36 survey in 901 headache patients. Pain 2001; 89(2-3):285-292.

20. Meletiche DM, Lofland JH, Young WB. Quality of life differences between patients with episodic and transformed migraine. Headache 2001; 41:573-578.

21. Verri AP, Cecchini P, Galli C, Granella F, Sandrini G, Nappi G. Psychiatric comorbidity in chronic daily headache. Cephalalgia 1998; 18(Suppl 21):45-49.

22. Grazzi L, Andrasik F, D'Amico D, Leone M, Usai S, Kass SJ et al. Behavioral and pharmacologic treatment of transformed migraine with analgesic overuse: outcome at 3 years. Headache 2002; 42(6):483-490.

23. Lipchik GL, Nash JM. Cognitive-behavioral issues in the treatment and management of chronic daily headache. Cur Pain Headache Rep 2002; 6:473-479.

24. Holroyd KA, O'Donnell FJ, Stensland M, Lipchik GL, Cordingley GE, Carlson BW. Management of chronic tension-type headache with tricyclic antidepressant medication, stress management therapy, and their combination: a randomized controlled trial. JAMA 2001; 285(17):2208-2216.

25. Lake AE. Behavioral and nonpharmacological treatments of headache. Med Clin N Am 2001; 85:1055-1075.

26. Redillas C, Solomon S. Prophylactic pharmacological treatment of chronic daily headache. Headache 2000; 40(2):83-102. 